\title{
Pelatihan Pembuatan Laporan Kerja Menggunakan Microsoft Excel Guna Mendukung Keahlian Staff Desa Kota Batu
}

\author{
Lilyani Asri Utami', Eka Rini Yulia², Siti Ernawati ${ }^{3}$, Hylenarti Hertyana ${ }^{4}$, \\ 1,2,3,4 Sekolah Tinggi Manajemen Informatika dan Komputer Nusa Mandiri \\ e-mail: ${ }^{1}$ lilyani.lau@nusamandiri.ac.id, ${ }^{2}$ eka.erl@nusamandiri.ac.id, \\ ${ }^{3}$ siti.ste@nusamandiri.ac.id, ${ }^{4}$ hylenarti.hha@nusamandiri.ac.id
}

\begin{abstract}
Abstrak
Perkembangan teknologi yang begitu pesat diberbagai bidang mengharuskan masyarakat mengikuti setiap perkembangannya. Hal ini dilakukan untuk dapat memperoleh informasi yang dibutuhkan. Salah satunya adalah penggunaan Microsoft Excel dalam pengolahan data. Hampir seluruh masyarakat baik organisasi, dunia pendidikan, instansi pemerintahan maupun swasta memanfaatkan microsoft excel. Penggunaan dari microsoft excel dapat meningkatkan kualitas dan profesionalitas pekerja dalam mengolah data. Para staff yang ada memiliki keterbatasan mengakses informasi dan mencari media pelatihan dalam pembelajaran untuk meningkatkan keahlian dalam mengolah data. Berdasarkan hasil pemikiran tersebut maka staff Desa Kota Batu membutuhkan pelatihan Microsoft Excel. Metode yang akan diterapkan dalam kegiatan pengabdian masyarakat ini adalah ceramah untuk memberikan penjelasan mengenai teori dan simulasi serta tanya jawab untuk metode praktikumnya. Dengan diadakannya pelatihan ini, para staff Desa Kota Batu dapat mengembangkan kemampuan dan kemahirannya dalam mengolah data untuk menyajikan laporan kerja yang lengkap, otomatis, dan lebih akurat.
\end{abstract}

Kata Kunci: Laporan Kerja; Microsoft Excel; Pelatihan; Staff Desa Kota Batu

\begin{abstract}
The rapid development of technology in various fields requires that people follow every development. This is done to be able to obtain the information needed. One of them is the use of Microsoft Excel in the data processing. Almost the entire community organizations, education, government, or private agencies utilizing Microsoft Excel. The use of Microsoft Excel can improve the quality and professionalism of workers in processing the data. The staff have very limited access to information and search for media training in learning to improve skills in the data processing. Based on the results of such thought, then the staff of Desa Kota Batu requires training in Microsoft Excel. The method will be applied in community service activities this is a lecture to explain the theory and simulation as well as faqs for methods practicum. With this training, the staff of Desa Kota Batu can develop the ability and skills to process the data for the present work reports a complete, automated, and more accurate.
\end{abstract}

Kata Kunci: Work Report; Microsoft Excel; Training; Staff of Desa Kota Batu 


\section{Pendahuluan}

Teknologi informasi yang terus berkembang mengharuskan masyarakat untuk mengikuti setiap perkembangannya. Salah satunya adalah penggunaan program yang sering digunakan yaitu produk dari Microsoft Office salah satunya Microsoft Excel dalam pengolahan data (Petro \& Swatan, Handoko, 2019). Hampir seluruh masyarakat baik organisasi, dunia pendidikan, instansi pemerintahan maupun swasta memanfaatkan Microsoft Excel. Penggunaan dari Microsoft Excel dapat membantu meningkatkan kualitas dan profesionalitas pekerja dalam mengolah data. Fungsi program excel untuk mengolah data secara otomatis seperti perhitungan, rumus, pemakaian fungsi, tabel, pembuatan grafik dan manajemen data (Abdullah, Millenia, Nusfiana, Ariance, \& Krisnawati, 2019). Microsoft Excel dapat disajikan dalam bentuk grafik untuk pelaporan kerja pada setiap instansi. Hampir seluruh masyarakat baik organisasi, dunia pendidikan, instansi pemerintahan maupun swasta menggunakan teknologi informasi salah satunya microsoft Excel (Sormin, Sahara, \& Agustina, 2018). Microsoft Excel telah dikenal luas oleh masyarakat sebagai sebuah aplikasi lembar kerja yang dapat dimanfaatkan dan sangat membantu dalam kegiatan pengolahan data. Microsoft Excel memiliki banyak fitur dan dapat mengolah data dengan menggunakan rumus-rumus yang sudah tersedia. Penggunaan dari Microsoft Excel dapat meningkatkan kualitas dan profesionalitas pekerja dalam mengolah data(Yusri, Edriati, \& Yuhendri, 2020).

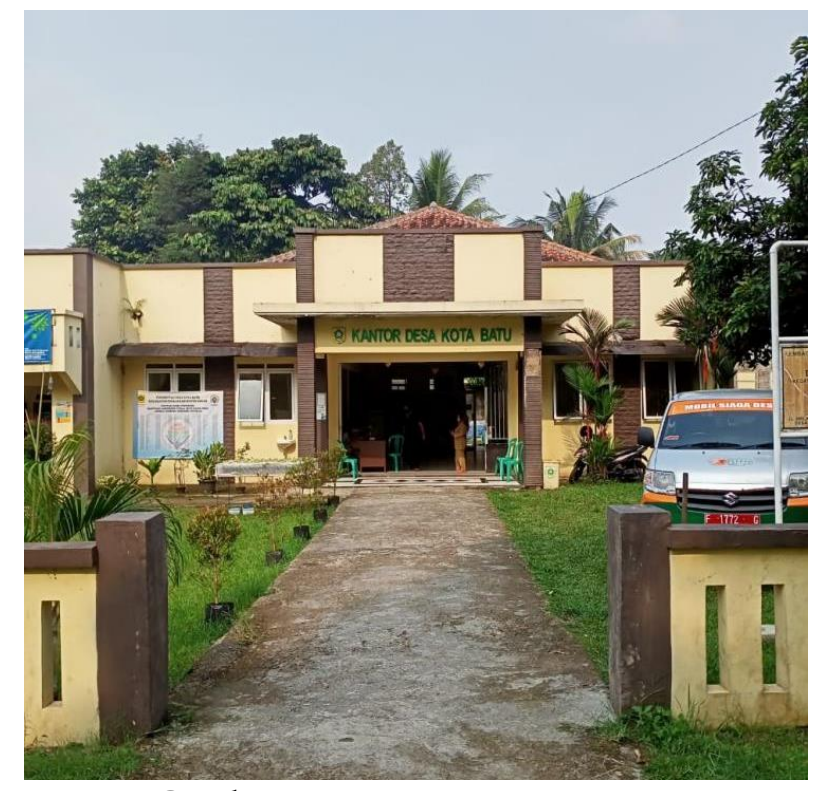

Gambar 1. Kantor Desa Kota Batu

Kantor Desa Kota Batu Kecamatan Ciomas beralamat di Jalan Melati Komplek Paspampres RT. 02/ RW. 09 Desa Kota Batu Kecamatan Ciomas Kabupaten Bogor. Gambar 1 merupakan Kantor Desa Kota Batu tampak depan. Kantor Desa Kota Batu ini di kepalai oleh Kepala Desa atau Lurah yaitu Bapak Iwan Darmawan, SH. Jumlah penduduk pertahun 2019 yang ada di Desa Kota Batu ini adalah 24.942 orang, dengan jumlah kepala keluarga sebanyak 6.005. Kantor Desa Kota Batu ini memiliki banyak staff yang bekerja. Permasalahan yang didapatkan berdasarkan hasil analisa bahwa 
Staff Kantor Desa Kota Batu masih kurang memahami pemanfaatan Microsoft Excel guna membuat laporan kerja yang akurat disertai dengan grafik. Selain itu Staff Kantor Desa Kota Batu juga belum banyak yang memahami dengan detail dalam pengoperasian Microsoft Excel serta cara mengimplementasikannya. Berdasarkan hasil pemikiran tersebut maka Sekolah Tinggi Manajemen Informatika dan Komputer Nusa Mandiri Nusa Mandiri menyelenggarakan pengabdian masyarakat kepada Staff Desa Kota Batu mengenai pengolahan data menggunakan Microsoft Excel dalam pembuatan laporan kerja. Hal tersebut terkait dengan perhatian institusi dilakukan dengan memperhatikan salah satu bidang strategis yaitu pembangunan ekonomi Indonesia (Yulia, Ernawati, Purnamasari, Wasesha, \& Ryansyah, 2019).

Tujuan utama dari kegiatan pengabdian masyarakat ini adalah meningkatkan kemampuan staff Desa Kota Batu dalam mengolah data menggunakan Microsoft Excel untuk kehidupan sehari-hari terutama digunakan untuk mengetahui bagaimana cara untuk mengolah data-data berupa perhitungan aritmatika dan khususnya untuk pelaporan kerja.

\section{Metode}

Pengabdian masyarakat dilaksanakan menggunakan metode ceramah dengan teknik presentasi materi dilanjutkan dengan diskusi, sedangkan praktikum secara langsung dikemas dalam bentuk workshop. Peserta kegiatan pengabdian masyarakat ini adalah Staff Kantor Desa Kota Batu juga belum banyak yang memahami dengan detail dalam pengoperasian Microsoft Excel. Kegiatan ini diadakan pada hari Sabtu, tanggal 06 Maret 2021 yang dihadiri oleh 14 orang staff Desa Kota Batu. Adapun tahapan pelaksanaan pengabdian kepada masyarakat dapat dilihat pada gambar 2 .

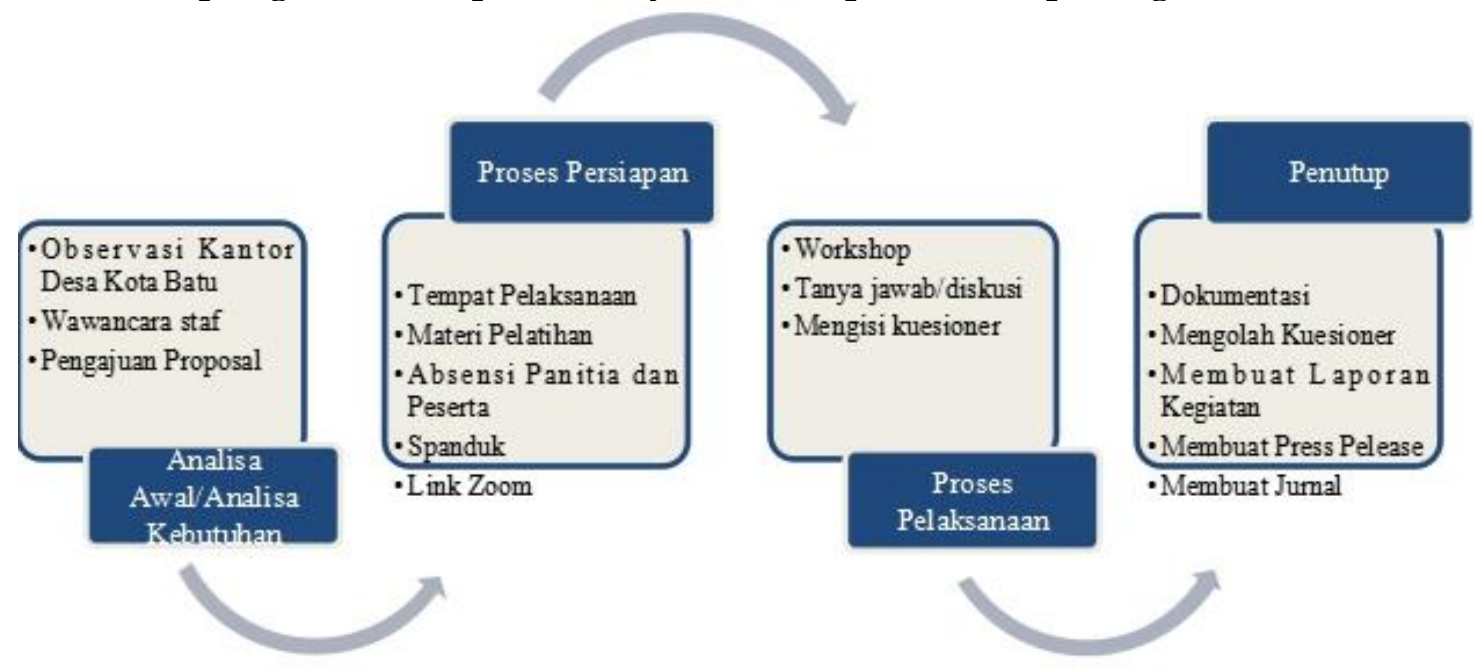

Gambar 2. Skema Pelaksanaan Pengabdian Kepada Masyarakat

Berikut ini adalah penjelasan dari gambar 2 yaitu skema pelaksanaan pengabdian kepada masyarakat yang telah dilakukan.

1. Analisa awal atau analisa kebutuhan. Pada tahap ini kelompok pengabdi melakukan survey pendahuluan untuk melihat kondisi di lapangan dalam hal ini Kantor Desa Kota Batu dan wawancara kepada staff dengan protokol kesehatan 
yang tertib. Dalam tahap ini dicari kendala dan permasalahan yang dihadapi oleh para staff dalam mengolah laporan kerja sehari-hari yang akurat dan otomatis, setelah itu membuat pengajuan proposal kegiatan pengabdian berdasarkan analisa kebutuhan.

2. Persiapan kegiatan pengabdian yang meliputi persiapan tempat pelaksanaan, materi pelatihan, absensi panitia dan peserta, spanduk, serta link zoom.

3. Proses pelaksanaan pengabdian dengan metode workshop, diskusi, dan tanya jawab. Peserta melakukan kegiatan pembuatan laporan kerja dengan pengolahan data dan grafik menggunakan Microsoft Excel dalam bentuk pelatihan yang disampaikan oleh tutor yang dibantu dan didampingi oleh dosen dan mahasiswa, dilanjutkan dengan tanya jawab/diskusi. Setelah itu evaluasi dilakukan dengan memberikan form kuesioner yang telah disiapkan oleh panitia untuk mengetahui seberapa puas peserta terhadap keseluruhan rangkaian kegiatan pengabdian. Masukan dan perbaikan lebih lanjut dapat dilakukan pada tahap ini.

4. Penutup, panitia mendokumentasikan kegiatan berupa foto-foto baik secara langsung maupun via zoom, merekap dan mengolah data kuesioner, membuat laporan kegiatan, membuat press release dan jurnal pengabdian masyarakat.

\section{Hasil dan Pembahasan}

Sekolah Tinggi Manajemen Informatika dan Komputer Nusa Mandiri yang diketuai oleh Ibu Lilyani Asri Utami, M.Kom dibantu ketiga dosen Ibu Eka Rini Yulia, M.Kom, Ibu Siti Ernawati, M.Kom, Ibu Hylenarti Hertyana, M.Kom dan lima mahasiswa Program Studi Sistem Informasi diantaranya Salfa Violita Adinda Putri, Satria Maulana Rendyto, Suci Rahmawati, Nadya Aprilia Rahman, Ahmad Fahrozi mengadakan Pengabdian Kepada Masyarakat berupa pelatihan pembuatan laporan kerja dengan pengolahan data dan grafik menggunakan Microsoft Excel guna mendukung keahlian staff Desa Kota Batu. Adapun materi pelatihan yang diberikan kepada peserta berupa latihan soal membuat nota pengiriman penjualan pakaian muslim. Gambar 1 penyampaian materi melalui aplikasi zoom.

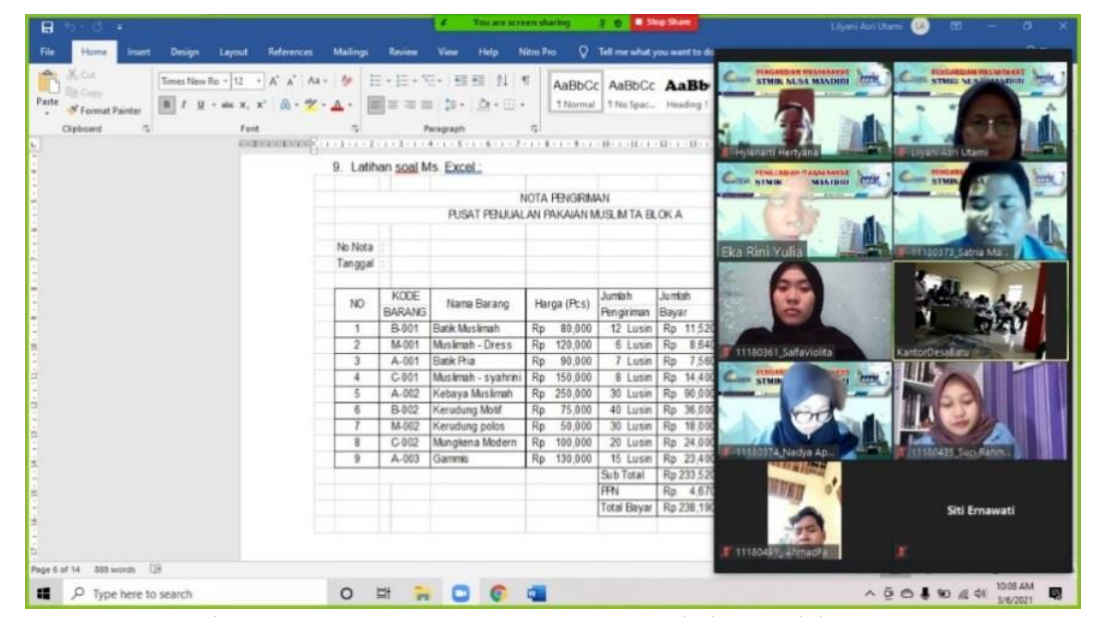

Gambar 3. Penyampaian materi melalui aplikasi zoom

Kegiatan pelatihan ini diadakan selain menjadi salah satu kewajiban bagi seorang dosen dalam melaksanakan tridharma perguruan tinggi, juga diharapkan dapat 
membantu para staff Desa Kota Batu meningkatkan kemampuan mengolah data untuk membuat laporan kerja. Pelatihan Microsoft Excel ini sangat dibutuhkan bagi peserta dikarnakan untuk meningkatkan pemahaman dalam menggunakan Microsoft Excel untuk kehidupan sehari-hari terutama digunakan untuk mengetahui bagaimana cara untuk mengolah data-data berupa perhitungan aritmatika dan lainnya.

Kegiatan ini dilaksanakan dengan tetap memperhatikan himbauan dari pemerintah dengan menerapkan protokol kesehatan diantaranya mengenakan masker, menjaga jarak dan melaksanakan pelatihan melalui Aplikasi Zoom. Pelatihan ini telah dilaksanakan pada hari Sabtu, tanggal 06 Maret 2021 yang dihadiri oleh 14 orang staff Desa Kota Batu. Penyampaian materi oleh Ibu Eka Rini Yulia, M.Kom ini telah berlangsung dan berjalan dengan lancar dengan didahului penyampaian materi teori berupa ceramah kemudian dilanjutkan dengan praktikum berupa simulasi dan Tanya jawab. Peserta diberikan kebebasan untuk bertanya dan berdiskusi mengenai materi yang disampaikan. Setelah penyampaian materi berupa teori dan praktek, diakhir acara, peserta diberikan latihan soal berupa kuis sesuai materi yang baru saja disampaikan. Dari hasil latihan soal yang diberikan kepada peserta, dapat dilihat perbedaan peserta dari sebelum kegiatan dan setelah kegiatan pelatihan menjadi lebih paham dalam mengoperasikan Microsoft Excel. Kegiatan ini dianggap sangat bermanfaat dalam menambah dan memperluas pengetahuan peserta dalam bidang teknologi informasi terutama dalam mengoperasikan Microsoft Excel, sehingga dapat langsung diterapkan dan dimanfaatkan dalam meningkatkan kualitas diri dalam dunia kerja dan membekali peserta untuk memiliki kemampuan mengoperasikan Microsoft Excel.

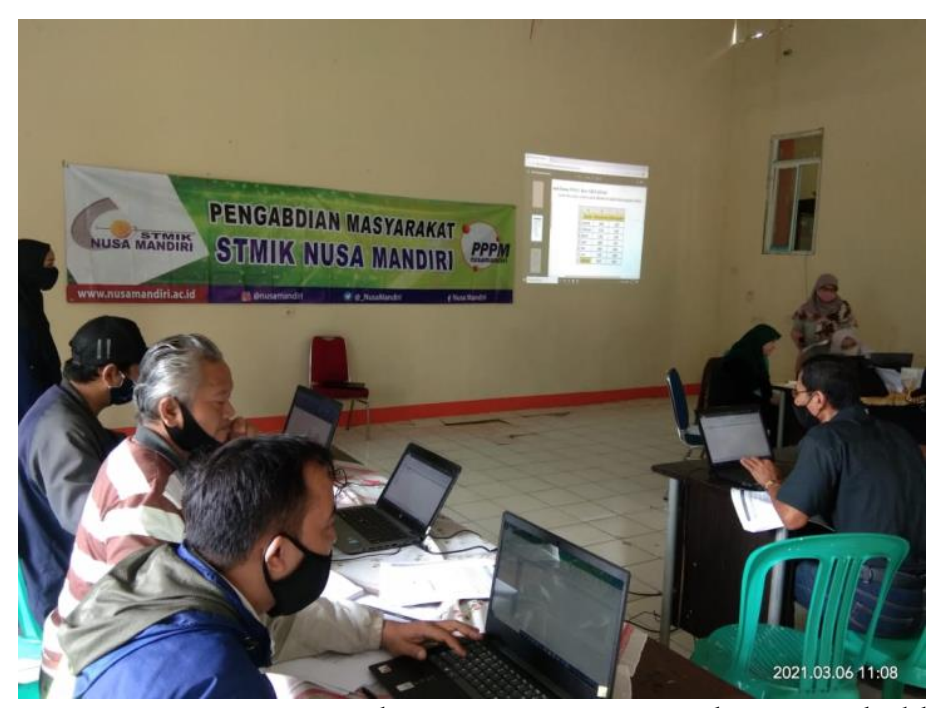

Gambar 4. Penyampaian materi dengan tetap menerapkan protokol kesehatan

Kepuasan peserta terhadap kegiatan ini dapat dilihat dari hasil kuesioner yang disebarkan kepada peserta dan respon yang baik dari para peserta pelatihan. Berdasarkan hasil evaluasi yang dilakukan dengan pengisian kuesioner kepada peserta pelatihan diperoleh hasil bahwa seluruh peserta merasa puas dengan diadakannya pelatihan ini. Peserta memberikan masukan yang sangat baik mengenai pelatihan ini dan berharap agar dapat diadakan kembali pelatihan seperti ini diwaktu 
yang akan datang. Responden yang mengisi kuesioner sebanyak 14 orang. Hasil pengolahan kuesioner dibuat dalam bentuk grafik yang dapat dilihat pada Gambar 4 merupakan grafik hasil kuesiner kegiatan pengabdian masyarakat.

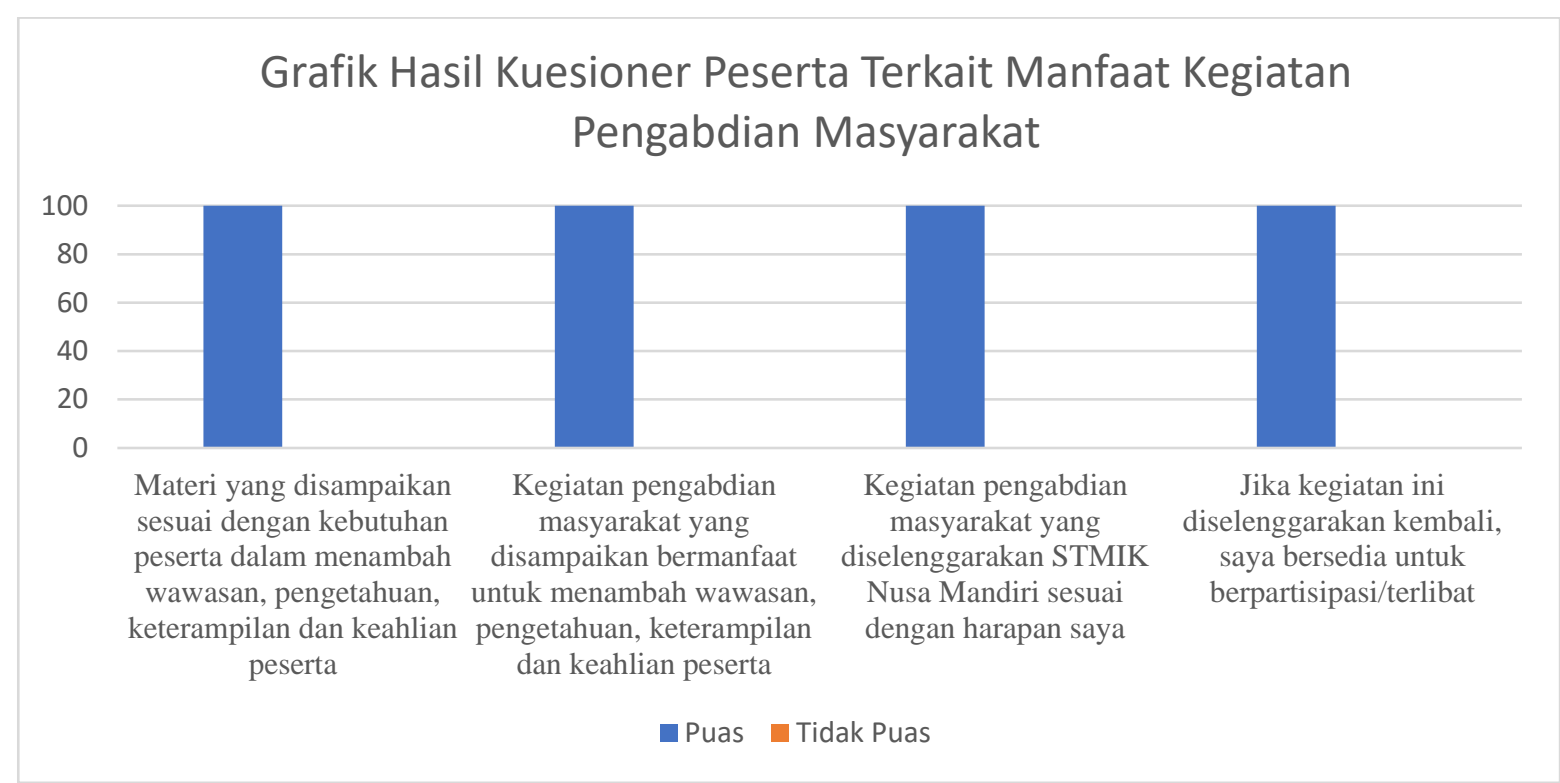

Gambar 5. Grafik Hasil Kuesioner Pengabdian Masyarakat

\section{Simpulan dan Rekomendasi}

Pelatihan pembuatan laporan kerja dengan menggunakan Microsoft Excel yang diadakan pada kantor Desa Kota Batu telah dilaksanakan dan berlangsung dengan lancar. Melihat tingginya antusias para staff mengikuti kegiatan tersebut menunjukkan bahwa para staff menyadari betapa pentingnya pelatihan ini guna mendukung keahliannya. Hal ini dikarenakan dengan adanya pelatihan penggunaan Microsoft Excel ini, menjadi lebih mudah dan cepat dalam membuat laporan kerja.

Rekomendasi yang dapat diberikan untuk kegiatan berikutnya adalah dapat dilakukan secara berkala serta dapat meningkatkan sarana dan prasarana agar memudahkan para staff dalam mengikuti kegiatan ini kedepannya.

\section{Daftar Pustaka}

Abdullah, D., Millenia, D., Nusfiana, D., Ariance, E., \& Krisnawati, F. (2019). Persamaan dan Perbedaan Microsoft Excel. 2016-2018.

Petro, S., \& Swatan, Handoko, K. (2019). Pelatihan Microsoft Excel Sebagai Penunjang Ketrampilan Hard Skill Bagi Siswa Pada SMK YPSEI Palangka Raya. Jurnal ABDIMAS BSI, 2(2), 280-286.

Sormin, M. A., Sahara, N., \& Agustina, L. (2018). Pelatihan Pemanfaatan Perangkat Lunak (Microsoft Office Word, Excel, Power Point) Dalam Kinerja Pengolahan Data Di Pemerintahan Desa Bagi Kepala Desa Se-Kecamatan Batang Angkola. MARTABE : Jurnal Pengabdian Masyarakat, 1(2), 78-82. 
Yulia, E. R., Ernawati, S., Purnamasari, I., Wasesha, D. A., \& Ryansyah, M. (2019). Pelatihan Microsoft Word Dengan Materi Desain Surat Lamaran Kerja dan Curriculum Vitae ( CV ). Jurnal ABDIMAS Nusa Mandiri, 1(2), 5-10.

Yusri, R., Edriati, S., \& Yuhendri, R. (2020). Pelatihan Microsoft Office Excel Sebagai Upaya Peningkatan Kemampuan Mahasiswa Dalam Mengolah Data. Rangkiang: Jurnal Pengabdian Pada Masyarakat, 2(1), 32-37. 